\title{
Zmo0994, a novel LEA-like protein from Zymomonas mobilis, increases multi-abiotic stress tolerance in Escherichia coli
}

\author{
Jungwoo Yang ${ }^{1}$, Ha Eun Kim', Young Hoon Jung ${ }^{2}$, Jungyeon Kim', Do Hyoung Kim', Adrian R. Walmsley ${ }^{3}$ \\ and Kyoung Heon Kim ${ }^{1 *}$ (D)
}

\begin{abstract}
Background: Pretreatment processes and subsequent enzymatic hydrolysis are prerequisites to utilize lignocellulosic sugar for fermentation. However, the resulting hydrolysate frequently hinders fermentation processes due to the presence of inhibitors and toxic products (e.g., ethanol). Thus, it is crucial to develop robust microbes conferring multi-stress tolerance.
\end{abstract}

Results: Zmo0994, a functionally uncharacterized protein from Zymomonas mobilis, was identified and characterized for the first time. A major effect of Zmo0994 was a significant enhancement in the tolerance to abiotic stresses such as ethanol, furfural, 5'-hydroxymethylfurfural and high temperature, when expressed in Escherichia coli. Through transcriptome analysis and in vivo experiments, the cellular mechanism of this protein was revealed as due to its ability to trigger genes, involved in aerobic respiration for ATP synthesis.

Conclusions: These findings have significant implications that might lead to the development of robust microbes for the highly efficient industrial fermentation processes.

Keywords: Abiotic stress, Inhibitors, Multi-stress tolerance, Zmo0994, Zymomonas mobilis

\section{Background}

Recent climate changes due to the long-term use of fossil fuels have necessitated the development of renewable non-fossil fuels, such as bioethanol, to meet increasing global energy needs [1]. Bioethanol is a product of microbial fermentation of sugars from starch and, more recently, lignocellulosic biomass [2]. Lignocellulosic biomass is generally referred to as non-food biomass and is obtained from other organic sources such as wood, grass, and various wastes, which are recalcitrant to natural degradation [2]. Thus, pretreatment and subsequent enzymatic hydrolysis are prerequisites to

\footnotetext{
*Correspondence: khekim@korea.ac.kr

1 Department of Biotechnology, Graduate School, Korea University, Seoul 02841, Republic of Korea

Full list of author information is available at the end of the article
}

utilizing the lignocellulosic sugar for fermentation [3]. This pretreatment, using such as dilute acid at an elevated temperature, is effective for the hydrolysis of pentose polymers in hemicellulose, increasing the access of cellulases to cellulose fibers [4]. However, the resulting hydrolysate by this diluted acid pretreatment, which is most widely employed on an industrial scale, frequently hinders fermentation processes due to the presence of inhibitors, such as furfural and $5^{\prime}$-hydroxymethylfurfural (HMF) [5]. In addition to the presence of such inhibitors, hydrolysate fermentation on an industrial scale generally occurs under environmental stresses, such as temperature fluctuation, hyper-osmosis, and accumulation of toxic end products that inhibit fermentation, thereby resulting in reduced yield [6]. Although several processes are employed to alleviate these stresses and improve fermentation efficiency (e.g., detoxification 
using activated carbon for HMF) [5], the development of robust microbes with multi-stress tolerance is considered the key to enhancing the efficiency of industrial fermentation processes [7].

To date, various strategies have been applied for the improvement of microbial stress tolerance: (1) single or multi-gene manipulation, using such as multi-drug efflux pumps (e.g., acrAB-tolC) [8] and chaperones (e.g., groESR and dnaKJE) [9]; (2) phenotype(s) screening from random mutagenesis libraries constructed by molecular engineering (e.g., gTME) [10]; (3) adaptive evolution under selective pressure [11]; (4) direct evolution engineering using genome shuffling [12]; and (5) omics-analysis for systems biology, providing an insight into the tolerance mechanism and new targets for further manipulations [13]. Despite the numerous efforts, tolerance engineering remains at the laboratory stage [14]. Furthermore, tolerance engineering of microbes was still focused on genetic manipulation of the target genes from the eubacterial or bacterial kingdoms which are of known or expected function. Thus, it should be worthwhile (1) to explore functionally unknown genes in microorganisms and (2) to examine genes in higher organisms, which maintain life in harsh environments, to construct robust microbes for industrial application $[15,16]$. For example, the complete genome sequence of Zymomonas mobilis indicates that $32.6 \%$ of the 1998 protein-coding genes are still functionally unknown or have no similarity with functionally identified genes [17]. Another example is a functionally unknown protein from plants. Recently, the late embryogenesis abundant (LEA) proteins are revealed to have protective roles against drought, high salinity, and extremely high temperature $[18,19]$. Recently, heterogeneous expression of an LEA protein from Dendrobium officinale in Escherichia coli exhibited increased tolerance against high salinity and heat [20].

In this study, we isolated Zmo0994 from Z. mobilis, an uncharacterized protein that exhibits increased abundance in the culture supernatant under stress conditions. To utilize Zmo0994 as a tolerance-engineering tool, tolerance tests were performed against a variety of stresses by expressing the zmo0994 in E. coli. Then, the cellular mechanism of Zmo0994 was investigated through transcriptome analysis and in vivo experiments. Thus, this study has the potential to contribute significantly to the development of tolerant microbes that can improve the efficiency of industrial fermentation processes.

\section{Results}

\section{Identification of Zmo0994 overproduced under stresses} in Z. mobilis

As part of a project originally aimed at identifying low molecular-mass bacteriocins, we discovered that $Z$. mobilis secretes a number of proteins and one of them exhibits an increased abundance in the supernatant after the late exponential phase (Additional file 1: Figure S1). The protein secreted was unambiguously identified by mass spectrometry sequencing of tryptic fragments (Additional file 2: Figure S2); it was Zmo0994, a functionally uncharacterized protein but with partial homology to members of group-3 of the late embryogenesis abundant (LEA) protein family (Additional file 3: Figure S3). These are associated with tolerance to dehydration in a wide range of plant species [21]. The secreted Zmo0994 protein had a signal sequence indicative of its targeting the periplasm [22].

Typically, ethanol production by Z. mobilis occurs as cells grow. Thus, the secretion of Zmo0994 protein during the stationary phase might suggest that it plays a role in conferring ethanol tolerance to Z. mobilis. We hypothesized that the increase in ethanol concentration might trigger the secretion of Zmo0994. To test the hypothesis, ethanol fermentations were performed and the extracellular protein profiles from $Z$. mobilis were analyzed. After the complete consumption of glucose at $16 \mathrm{~h}$, the growth of $Z$. mobilis appeared to cease at around the $24 \mathrm{~h}$ time point, when the ethanol concentration reached a maximum $(35.1 \pm 0.3 \mathrm{~g} / \mathrm{L}$ in Fig. 1a). At $24 \mathrm{~h}$, the abundance of Zmo0994 protein was the highest among the secreted proteins (Fig. 1b). Subsequently, we sought to investigate whether the RNA expression level of zmo0994 is upregulated in the presence of ethanol stress in Z. mobilis using quantitative reverse transcription PCR (qRT-PCR). This qRT-PCR revealed that the expression level of zmo0994 was significantly higher after the exposure of the Z. mobilis to $6 \%(\mathrm{v} / \mathrm{v})$ of ethanol (Fig. 1c and Additional file 4: Figure S4). Therefore, it was confirmed that Zmo0994 expression is directly associated with ethanol stress in Z. mobilis.

\section{Multi-stress tolerance increased in E. coli harboring zmo0994}

Considering our previous observations, we sought to test whether Zmo0994 enhances abiotic stresses tolerance by expressing the zmo0994 gene in E. coli. To demonstrate this, E. coli BL21(DE3) cells were transformed with either empty vector (pET21a) or recombinant plasmid (pET21a::zmo0994), yielding E. coli Emp and E. coli ZM, respectively. The tolerance of these transformants were tested against a wide range of abiotic stresses, including ethanol (4-8\%, v/v), furfural (10-30 mM), hydroxymethylfurfural (HMF; $10-30 \mathrm{mM})$, and heat $\left(44-48{ }^{\circ} \mathrm{C}\right)$. A significant difference was observed in the growth of colonies, grown at either a $10^{-1}$ or $10^{-2}$ dilution, with the $E$. coli $\mathrm{ZM}$ strain producing a significantly higher number of colonies compared to E. coli Emp (Fig. 2a). Furthermore, 

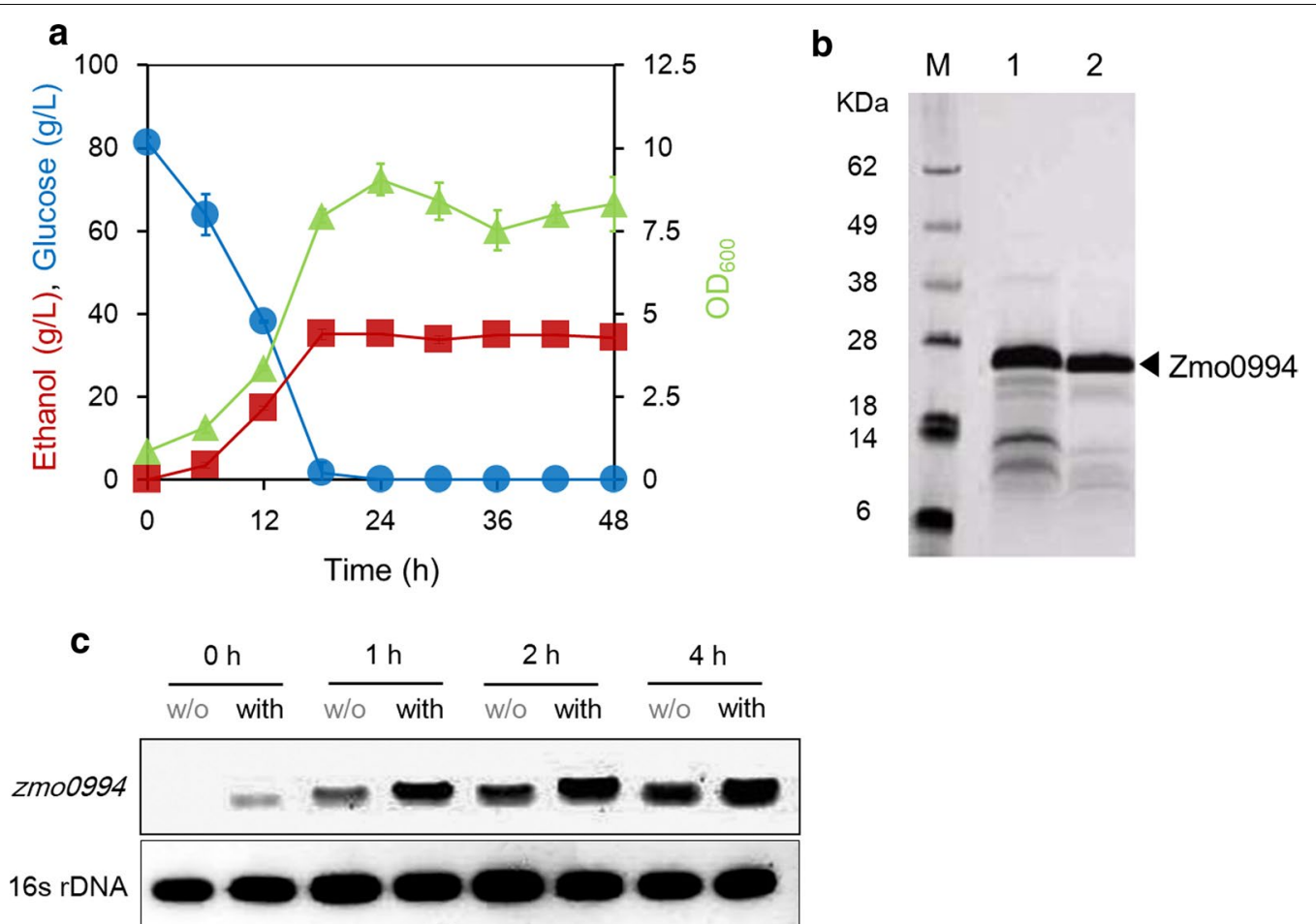

Fig. 1 Identification of Zmo0994 overproduced under stresses in Z. mobilis. a Fermentation profiles of Z. mobilis. Initial cell density was set to 0.5 of optical density at $600 \mathrm{~nm}\left(\mathrm{OD}_{600}\right)$ and cell growth, glucose and ethanol concentrations were monitored during ethanol fermentation. b Overproduction of Zmo0994 at $24 \mathrm{~h}$, when glucose was completely depleted and ethanol concentration was at the maximum. Figure was reprinted and adapted with permission from the reference [69]. c Quantitative RT-PCR analysis for zmo0994 expression in the absence and presence of ethanol in Z. mobilis. When the cell density of Z. mobilis grew to 0.5 of $\mathrm{OD}_{600}$, cells were either treated or non-treated with $6 \%(\mathrm{v} / \mathrm{v})$ ethanol. Then, the total RNA was isolated from Z. mobilis and was converted into CDNA. Finally, PCR was performed to amplify the partial fragment of zmo0994 (188 bp). As a housekeeping gene, partial fragment of $16 \mathrm{~s}$ ribosomal DNA (129 bp) was amplified as shown. The experimental data represent means \pm standard deviations from either two or three independent experiments

we sought to assess the viability of the transformant cells when exposed to different abiotic stresses: a viability assay was performed in which the survival of cells, using an equivalent initial CFU (colony-forming unit)/mL of $E$. coli $\mathrm{ZM}$ and $E$. coli Emp, was measured after exposure to ethanol, furfural, HMF, and heat stress for $12-24 \mathrm{~h}$. Significantly, the $E$. coli $\mathrm{ZM}$ cells had a mean viability ratio $\sim 9.3$-fold higher than that of the E. coli Emp cells under ethanol stress (Fig. 2b). In addition, the E. coli ZM transformants had a significantly higher viability ratio than $E$. coli Emp transformants after exposure to $20 \mathrm{mM}$ furfural, $20 \mathrm{mM}$ HMF, and heat stress (Fig. 2b).

\section{Correlation between expression level of Zmo0994 and stress tolerance in $E$. coli}

Furthermore, to substantiate that Zmo0994 is responsible for multi-stress tolerance in $E$. coli, we tested whether the stress tolerance of cells is significantly affected by the expression level of Zmo0994. In this test, ethanol was used as a model chemical for multi-stress tolerance. For fine-tuning the expression level, the $5^{\prime}$-untranslated region ( $5^{\prime}$-UTR) of the $z m o 0994$ gene was engineered [23]. Two synthetic $5^{\prime}$-UTRs, which were predicted to express different levels of Zmo0994, were introduced into the pET21a vector, yielding U1pET and U2pET plasmids (Fig. 3a). The resulting recombinant plasmids were transformed into E. coli BL21(DE3), yielding E. coli ZMU1 and $E$. coli ZMU2 strains, respectively. To determine the expression levels of $\mathrm{Zmo0994}$ regulated by the three different $5^{\prime}$-UTRs, a Western-blot analysis was performed. This Western-blot analysis indicated that the Zmo0994 expression levels regulated by the three $5^{\prime}$-UTRs varied according to the predictive expression levels (Fig. 3b and Additional file 5: Figure S5). Subsequently, to examine the effect of variation in the expression levels of Zmo0994 on ethanol tolerance, the E. coli transformants were incubated in LB media containing $0-6 \%(\mathrm{v} / \mathrm{v})$ ethanol (Fig. 3c). Although the E. coli ZM, E. coli ZMU1, and $E$. coli ZMU2 strains grew faster than $E$. coli Emp in the absence of ethanol, all the strains could grow up to $1.3-1.6$ of $\mathrm{OD}_{600}$ after $8 \mathrm{~h}$. In the presence of $4 \%$ ethanol, all the strains expressing Zmo0994 could grow up to 

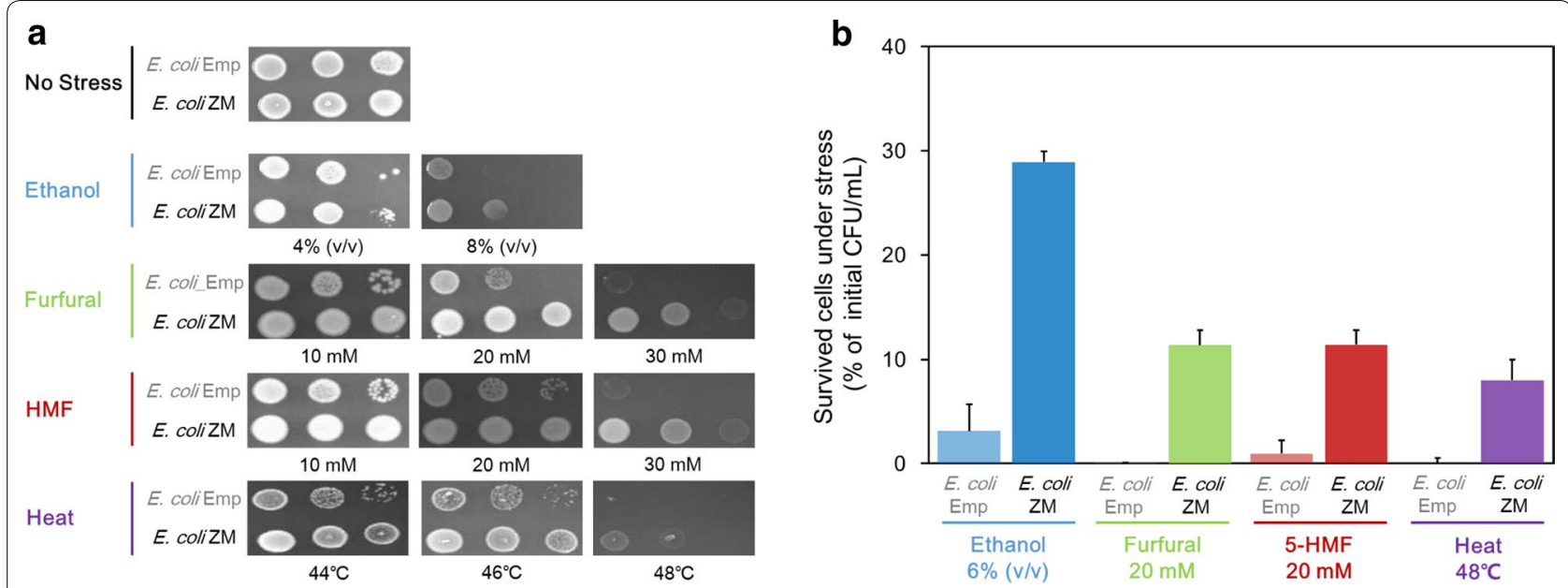

Fig. 2 Multi-stress tolerance increased in E. coli harboring zmo0994. a Spot assay under a variety of stresses. E. coli cells grown to 0.5 of $\mathrm{OD}_{600}$ were tenfold serially diluted, and were spotted onto LB agar plates containing $0.1 \mathrm{mM} \mathrm{IPTG}$ under various stresses. Then, each plate was incubated at $37-48^{\circ} \mathrm{C}$ for $16-24 \mathrm{~h}$. b Viability assay under a variety of stresses. E. coli cells grown to 0.5 of $\mathrm{OD}_{600}$ (approximately equivalent to $2.57 \times 10^{8} \mathrm{CFU} / \mathrm{mL}$ ) were harvested, washed, and transferred into fresh LB broth containing $0.1 \mathrm{mM}$ IPTG under various stresses. Then, aliquots were properly diluted and plated onto LB agar at 0,12 , and $24 \mathrm{~h}$ to determine CFU/mL. Finally, the viability of survived cells under various stresses was expressed as the percentage of initial CFU/mL after 12-24 h. The experimental data present means \pm standard deviations from three independent experiments

1.2 of $\mathrm{OD}_{600}$, while the E. coli Emp transformants ceased to grow after $2 \mathrm{~h}$, reaching 0.8 of $\mathrm{OD}_{600}$. In $6 \%$ ethanol, the E. coli ZMU2 cells, which showed the highest expression level of Zmo0994, exhibited the highest growth, specifically after $2 \mathrm{~h}$, while E. coli Emp cells exhibited an observable decrease in cell growth. Consequently, it was confirmed that an LEA-like protein, Zmo0994, from $Z$. mobilis was responsible for the multi-stress tolerance of E. coli.

\section{RNA-seq-based identification of genes underlying stress tolerance in E. coli harboring zmo0994}

Prior to investigating the impact of Zmo0994 on the cellular response of stress-tolerant $E$. coli ZM, we sought to identify the genes that are differentially expressed under ethanol stress $(4 \%, \mathrm{v} / \mathrm{v})$ in $E$. coli as a positive control, using both the E. coli ZM and E. coli Emp strains (Additional file 6: Figure S6 and Additional file 7: Tables S1 and S2). A number of well-known stress response genes were commonly up-regulated in both $E$. coli strains such as spy [24], asr [25], yjfO, rrlA, pspG [26], treBC, and $i b p A B$ [9]. However, $s r l B D E$ genes for osmotic stress [27, 28], $y q h D$ for oxidative stress response [29], pspAD for phage shock protein [26], as well as $n r d D$ for DNA synthesis and repair were distinctly up-regulated in $E$. coli $Z M$. In contrast, $\operatorname{sod} A$ and $\operatorname{sox} R$ for reactive oxygen species (ROS) response [30], aldA, acs, and glpK for glycerol, lactate, and acetaldehyde metabolism, respectively, and $c p x P$ [31], $p s p B$ [26], uspAF [32], and gnt $Y$ [33] for stress response were up-regulated in E. coli Emp, but not in E. coli ZM. Thus, we found that ethanol differentially induced genes for SOS response (the $\operatorname{sod} A$ and $\operatorname{sox} R$ ) in $E$. coli Emp and for osmotic stress response (the treBC and srlBDE) in E. coli ZM (Additional file 6: Figure S6). On the other hand, the genes that were down-regulated in response to ethanol stress were mostly those coding for membrane proteins (tsgA, ompGN, and yeaL) and membrane transporters (yqiG, garP, trkG, ycaM, malEK, and $m e l B$ ) (Additional file 6: Figure S6 and Additional file 8: Tables S3 and S4).

Considering that the expression of $z$ mo0994 in E. coli caused a distinct set of genes to be expressed, we further investigated those differentially expressed genes (DEGs) in response to Zmo0994 in the absence or presence of $4 \%$ (v/v) ethanol. Specifically, we focused our analysis on $>\log _{2}$ twofold genes by Zmo0994 expression, because we could not obtain a clear understanding of the functional significance in down-regulated genes (Additional file 9: Tables S5 and S6). Firstly, we collected 250 genes, which were commonly overexpressed in $E$. coli ZM compared to E. coil Emp in the presence and absence of ethanol stress (Additional file 10: Tables S7 and S8). Among these, we found that Zmo0994 triggered genes involved in a variety of stresses and genes inducible under oxygen-deprivation conditions: for instance, polA [34] and $n f s A$ [35] for oxidative stress; $p s d$, prfAB, and $p l s B$ regulated by RpoE $(\sigma 24)$ for heat stress [36, 37]; $h f l K X, h t p G$, and $d n a J$ regulated by $\mathrm{RpoH}(\sigma 32)$ for protease or chaperon [36, 37]; $c f a$ [38], yiiT (UV), dps (nutrient) [39], mutS (DNA repair) [40], $u v r B$ (UV) [41], and $\operatorname{cspD}$ [42] for general stresses; 


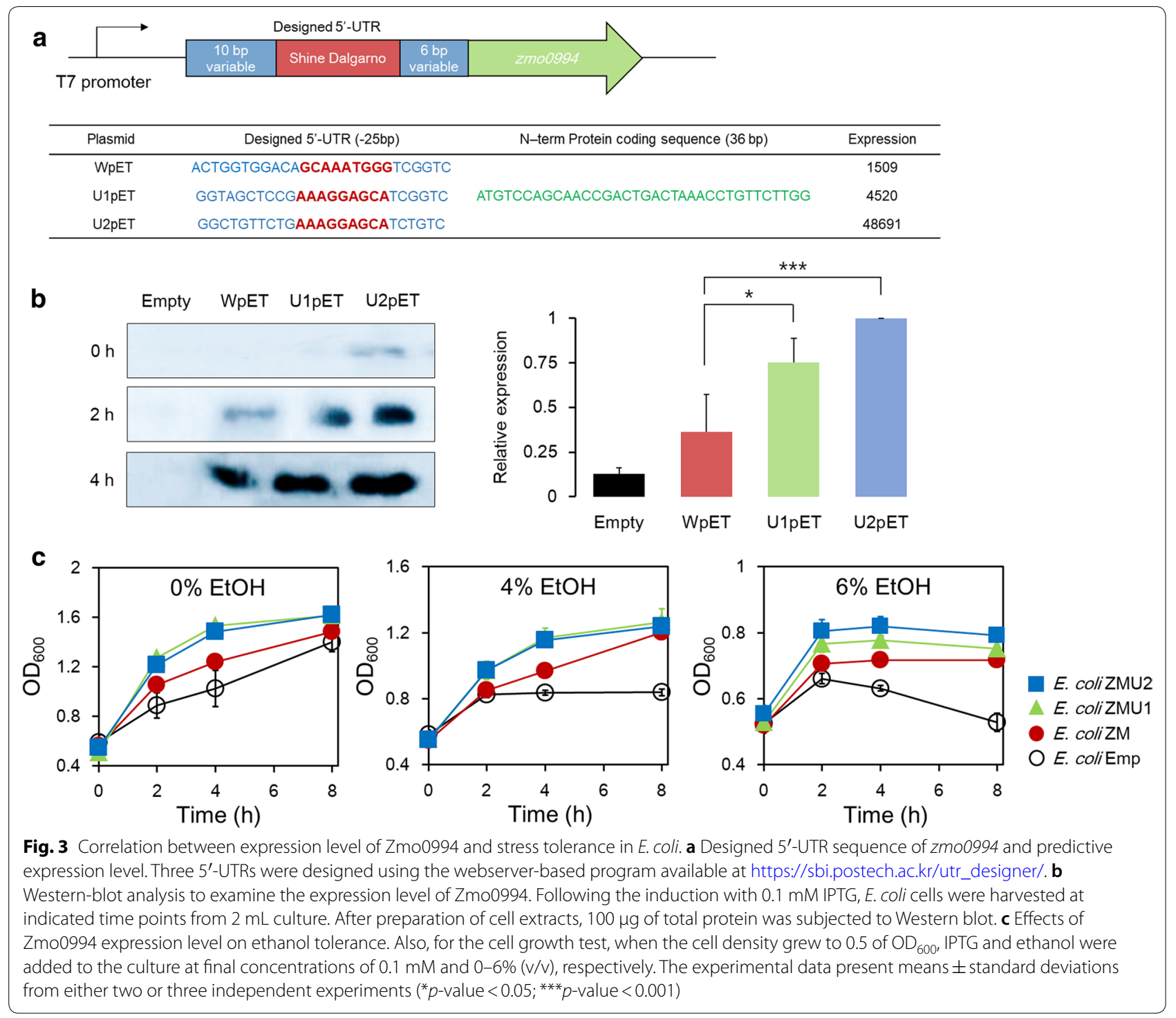

$g l p T, d c u A, a c e E, f a d A H$, and $p f l A$ for oxygen deprivation responses.

We further found that Zmo0994 triggered the expression of gene clusters involved in aerobic respiration (Fig. 4a): five genes for the TCA cycle ( $s d h B, m d h, s u c A B$, and $i c d$ ); eight genes for NADH dehydrogenase (nuоAB$C G I L M N)$; three genes for cytochrome ubiquinol oxidase $\left(\right.$ cydABD); and three genes for $\mathrm{F}_{0} \mathrm{~F}_{1}$-ATPase (atpABE) (Fig. 4). However, fumarate reductase complex, which is one of the electron transport chains in E. coli, was not up-regulated. Among the 19 genes, encoding for the components of ATP synthesis in aerobic respiration, the expression of 6 genes (nouI, $s d h B, c y d B, c y d D$, nuoB, and $s u c B$ ) was noticeably observed to be increased as much as

\section{(See figure on next page.)}

Fig. 4 Transcriptome analysis to understand cellular mechanism of ethanol tolerance by Zmo0994. a A graphical representation of DEGs in E. coli ZM as compared to E. coli Emp in the presence/absence of ethanol. b A putative regulatory pathway of E. coli in response to Zmo0994. The pathway was constructed based on the functional clustering of DEGs (Additional file 16: Figure S11). G6P glucose-6-phosphate, F6P fructose-6-phosphate, FDP fructose 1,6-biphosphate, T3P1 D-glyceraldehyde 3-phosphate, T3P2 glycerone phosphate, 13PDG 1,3-biphospho-D-glycerate, $P Y R$ pyruvate, ACCOA acetyl coenzyme A, ICIT isocitrate, AKG alpha-ketoglutarate, SUCCOA succinyl coenzyme A, SUC succinate, FUM fumarate, MAL malate, OA oxaloacetate, 6PG 6-phosphogluconate, RL5p ribulose 5-phosphate 


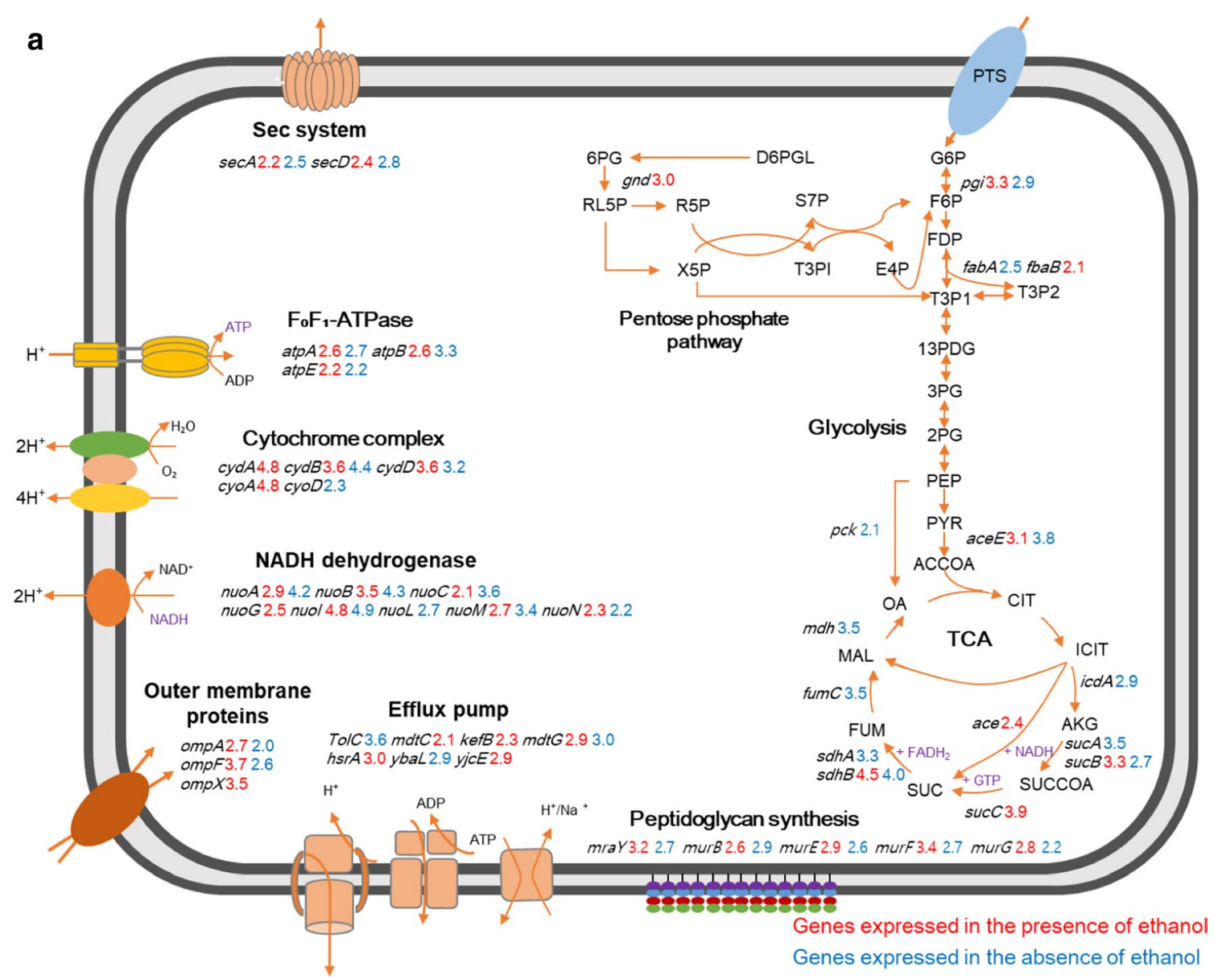

b

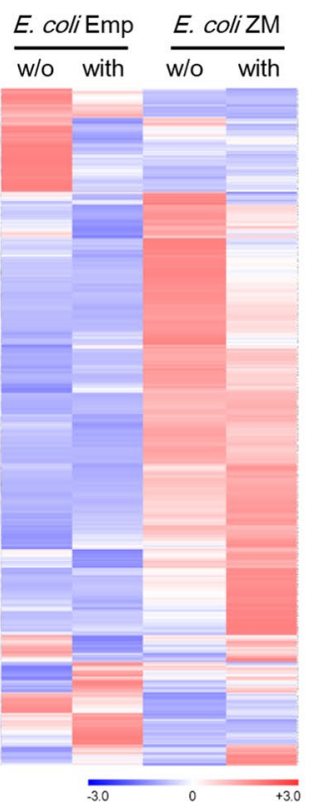

Genes with $>\log _{2} 2$-fold increase in their expression level in $E$. coli ZM as compared to $E$. coli $E m p$ in the presence/absence of ethanol, using a $p$-value threshold less than 0.05 .

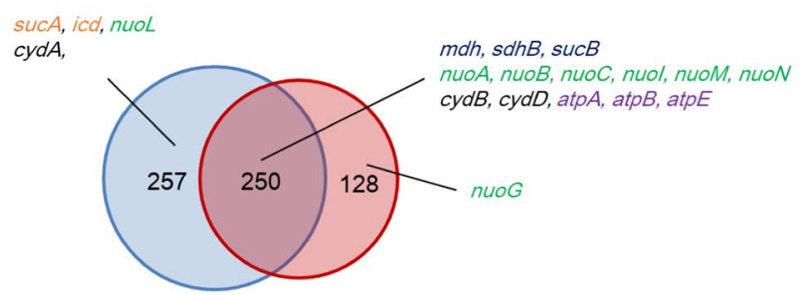

TCA cycle

$\mathrm{NADH}$ dehydrogenaise

Cytochrome complex

$\mathrm{F}_{0} \mathrm{~F}_{1}$-ATPase

Genes with $>\log _{2} 2$-fold decrease in their expression level in $E$. coli ZM as compared to $E$. coli Emp in the presence/absence of ethanol, using a $p$-value threshold less than 0.05 .

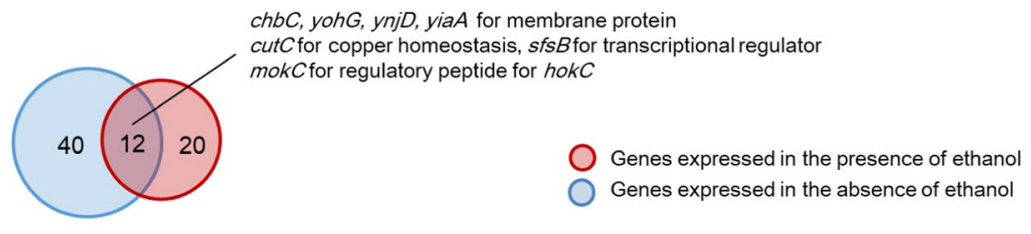


$\log _{2}$ threefold or greater: $4.84,4.51,3.59,3.58,3.45$, and 3.31, respectively. The $s u c A, i c d$, nuоL, and $c y d A$ genes were up-regulated only in the absence of ethanol stress, while the nuоG gene was up-regulated only in presence of ethanol stress by Zmo0994. Additionally, genes for efflux pumps (including the tolC) and for cell wall biogenesis (including the mur operon) were up-regulated. Finally, among the up-regulated 635 genes by Zmo0994 in the presence or absence of ethanol, those expected to be responsible for stress tolerance are summarized in Fig. 4b.

\section{ATP/ADP ratio}

Based on the transcriptome analysis (Fig. 4a), indicating that gene clusters involved in ATP synthesis were highly up-regulated in response to Zmo0994, it was hypothesized that Zmo0994 might improve ATP production, resulting in enhancement of cell viability under a variety of stresses. Thus, we measured intracellular ATP and ADP concentrations in the E. coli ZM and E. coli Emp cells in the absence and presence of ethanol. In results, time course measurements of the intracellular ATP/ADP ratio showed that $E$. coli $\mathrm{ZM}$ strain exhibits higher ATP/ADP ratio than E. coli Emp strain at $4 \mathrm{~h}$ regardless of ethanol stress (Fig. 5). More specifically, ATP/ADP ratio of E. coli ZM was observed to be 4.3- and 7.7-fold higher than that of E. coli Emp in

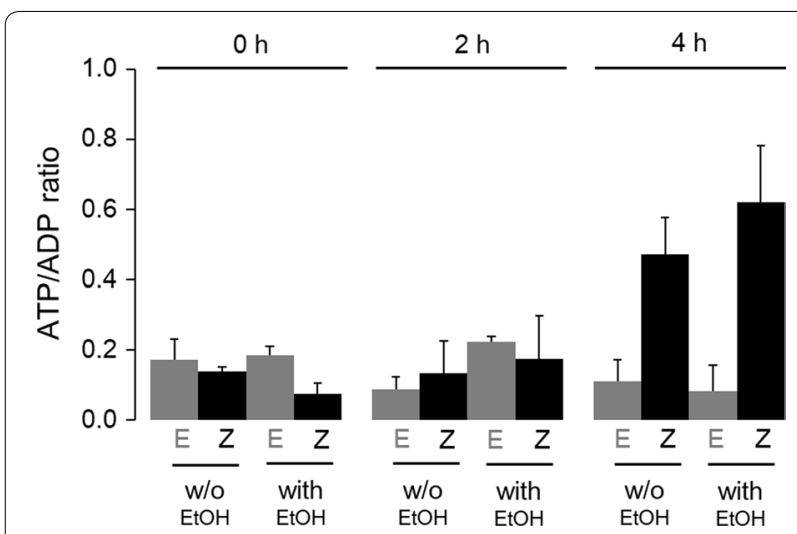

Fig. 5 Measurement of ATP/ADP ratio. When the cell densities of E. coli ZM and Emp strains grew to 0.5 of $\mathrm{OD}_{600}$, IPTG and ethanol were added to the culture at concentrations of $0.1 \mathrm{mM}$ and $4 \%(\mathrm{v} / \mathrm{v})$, respectively. Then, the intracellular ATP/ADP ratio was determined for $4 \mathrm{~h}$. The experimental data present means \pm standard deviations from three independent experiments the absence and presence of ethanol stress, respectively. Thus, these results demonstrated that the overexpression of Zmo0994 increased the intracellular ATP/ADP ratio, resulting in protection of cells against ethanol stress.

\section{In vivo validation of identified genes for stress tolerance}

Among the genes identified from the transcriptome analysis, we focused on the key genes clusters, which were distinctly up-regulated by Zmo0994. Thus, the genes for ATP synthesis under aerobic respiration, multi-drug efflux pump, and cell wall biogenesis were targeted to elucidate the mechanism of stress tolerance conferred by Zmo0994. More specifically, they were seven genes for the TCA cycle, eight genes for NADH dehydrogenase, four genes for cytochrome complex, two genes for FoF1-ATPase, six genes for multi-drug efflux pump, and six genes for cell wall biogenesis (Additional file 11: Table S9). For the stress tolerance tests, each of the 33 genes were independently expressed in E. coli BL21(DE3), with the transformants grown in the presence or absence of $4 \%(\mathrm{v} / \mathrm{v})$ ethanol and HMF (10 mM). The E. coli Emp and E. coli ZM strains were used as the negative and positive controls for the tolerance test. Firstly, we verified that E. coli $\mathrm{ZM}$ exhibited $>10$ - and $>2$-fold increase in the fitness compared to that of $E$. coli Emp under ethanol and HMF stress, respectively. Subsequently, we found that 20 and 14 out of the 33 tested genes significantly enhance ethanol and HMF tolerance, respectively, when expressed in E. coli BL21(DE3) (Fig. 6 and Additional file 12: Figures S7 and S8). Among them, the fitness of six genes (sucB, icdA, cydA, cyoB, kefB, and $m u r C$ ) showed $>10$-fold increase under ethanol stress compared to that of E. coli Emp, while the fitness of nine genes showed $>2$-fold increase under HMF compared to that of E. coli Emp (Fig. 6). Notably, overexpression of 11 genes in E. coli significantly increased both ethanol and HMF tolerance. These are $\operatorname{sucB}$ (dihydrolipoyltranssuccinylase), icdA (isocitrate dehydrogenase), nuoE (NADH:ubiquinone oxidoreductase, chain E), nuoG (NADH:ubiquinone oxidoreductase, chain E), cydD (glutathione/L-cysteine exporter), $\operatorname{atpA}$ (ATP synthase F1 complex, $\alpha$ subunit), tolC (outer membrane channel), $k e f B\left(\mathrm{~K}^{+}: \mathrm{H}^{+}\right.$antiporter), $\operatorname{murC}(\mathrm{UDP}-$ $\mathrm{N}$-acetylmuramate-alanine ligase), murD (UDP- $\mathrm{N}$-acetylmuramoyl-L-alanine:D-glutamate ligase), and murF (D-alanyl-D-alanine-adding ligase).

(See figure on next page.)

Fig. 6 In vivo validation of identified genes for stress tolerance. The relative fitness of $E$. coli harboring each gene involved in oxidative phosphorylation, electron transfer chain, efflux pump, and cell wall biogenesis under a ethanol (4\%, v/v) and b HMF (20 mM) stresses. E. coli BL21(DE3) harboring each gene was incubated in $100 \mathrm{~mL}$ of LB broth at $37^{\circ} \mathrm{C}$ for ethanol tolerance and was incubated in spectrophotometer (200 $\mathrm{LL}$ scale) for HMF tolerance. Finally, the relative fitness was calculated as described in "Methods". The experimental data present means \pm standard deviations from three independent experiments $\left({ }^{* *} p\right.$-value $<0.01$; ${ }^{* *} p$-value $<0.001$ ) 

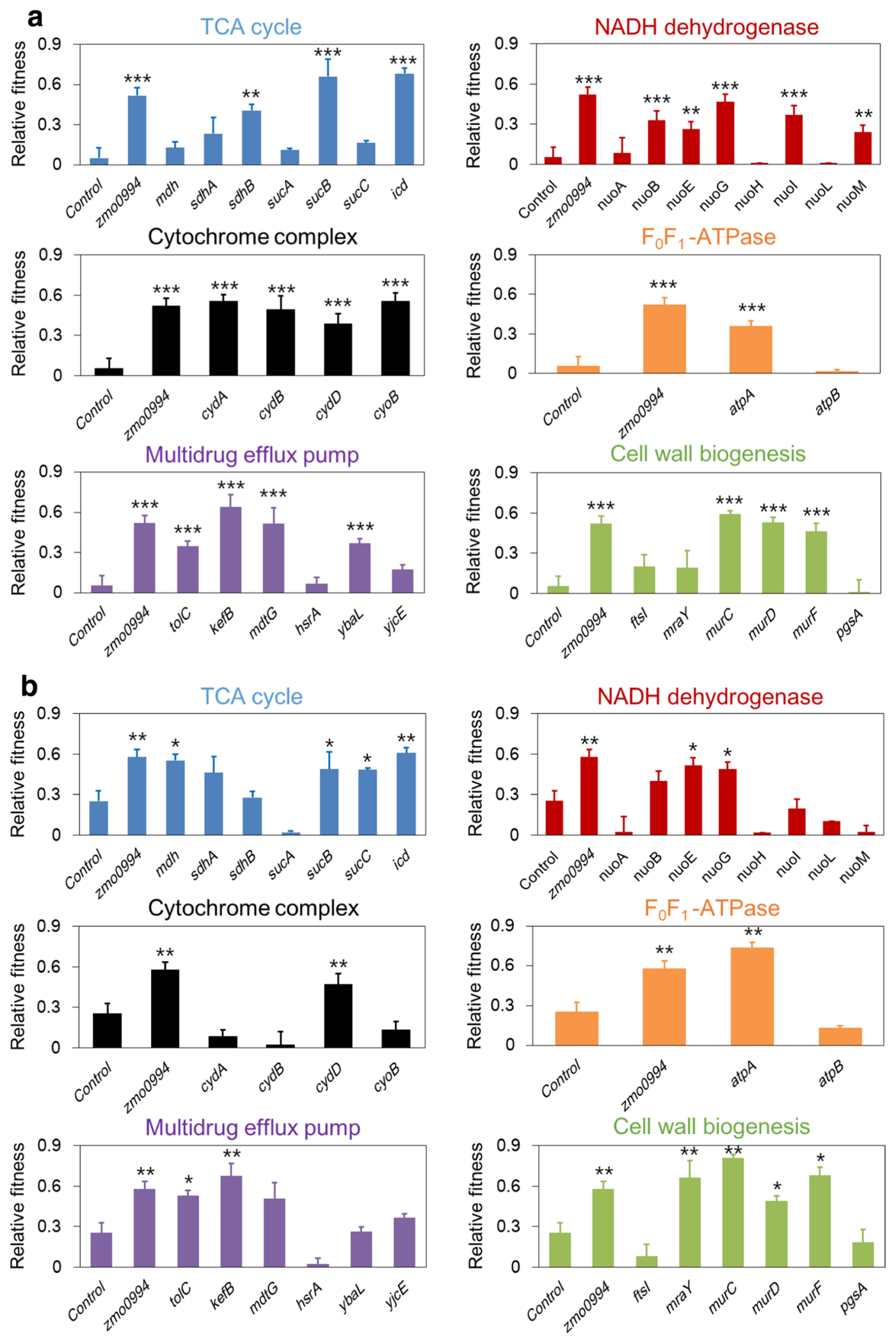


\section{Discussion}

Herein, we have discovered that Zmo0994 from the bacterium $Z$. mobilis, a novel LEA-like protein that is utilized by plant cells in protecting them against various stresses, such as dehydration, can confer tolerance to various abiotic stresses when expressed in E. coli. This is an important discovery, since it could provide a strategy for engineering an increase in the tolerance to abiotic stresses of bacterial strains used for fermentation processes. For example, a number of toxic compounds are produced during the pretreatment of lignocellulose, which act as inhibitors that hinder the fermentation process. Interestingly, while our initial expectation was that Zmo0994 would act to physically protect the cells from abiotic stresses similar to LEA proteins in plants, we discovered that it could regulate the expression of genes (e.g., genes for ATP synthesis) involved in conferring tolerance to abiotic stresses.

LEA proteins from plants have been shown to play a cellular protective role against hypersalinity, freezing, and temperature stresses $[18,19]$. It is proposed that under abiotic stress conditions, LEA may act as a chaperone to suppress desiccation-induced protein aggregation, a role that is likely potentiated by the interaction with non-reducing sugars such as trehalose and sucrose [21]. These sugars can also protect lipid membranes from abiotic stress that causes solute leakage and membrane protein aggregation [43]. The protective effect is due to the sugars forming a glassy matrix that prevents mechanical disruption and denaturation of membrane proteins. It has been shown that sucrose glasses are stabilized in vitro by interaction with LEA proteins [46]. A recent phylogenetic analysis suggests that the LEA protein from plants may have ancestral origins in the domains Bacteria and Archaea with acquisition endosymbionts or horizontal gene transfer [44]. Thus, it is not surprising that overexpression of LEA protein from plants increased tolerance against abiotic stresses in microorganisms [20,45].

LEA proteins have been grouped together with other osmotic stress-induced proteins from Saccharomyces cerevisiae and E. coli into a class of proteins termed hydrophilin, based on their high hydrophilicity index $(>1.0)$ and glycine content $(>6 \%)[46,47]$. Among these proteins, ribosome modulation factor (RMF), accumulates in $E$. coli upon growth transition from the exponential to the stationary phase [48], suggesting a role in stress tolerance like that of $\mathrm{Zmo0994}$. In yeast, the small heat shock protein 12 (HSP12) was first identified as a novel hydrophilin-like protein [49] and it has been generally regarded as a membrane-associated chaperone that confers tolerance against oxidative, thermal, and osmotic stresses [50, 51]. In this study, it was found that Zmo0094 can be grouped into the hydrophilin class of proteins

[46], when its N-terminal signal peptide, consisting of the first 33 amino acids of its sequence, was removed (Fig. 7a). Interestingly, a recent evolutionary data on LEA-like proteins from bacteria indicate that only 12 out of 26 LEA proteins have a signal peptide responsible for protein secretion [52]. To test whether the signal peptide of Zmo0994 affects ethanol tolerance, E. coli ZMsig(-) harboring $\mathrm{N}$-term-truncated $z m o 0994$ was constructed and was found to exhibit ethanol tolerance (Fig. 7b). Thus, establishing that Zmo0994 plays a role in the cytoplasm rather than, or in addition, to any role in the cell membrane, subsequently, we confirmed that GFP-fused Zmo0994 expressed in E. coli was localized in the cytoplasm rather than the cell membrane (Additional file 13: Figure S9). Because Zmo0994 induces up-regulation of a number of genes, it was hypothesized that it might function as an RNA chaperone. However, we cannot find any evidence supporting this notion in the experiment substituting cold shock protein [53] with Zmo0994 (Additional file 14: Figure S10).

Previous studies showed that ethanol mainly attacks the cell membrane and increases oxidative stress,
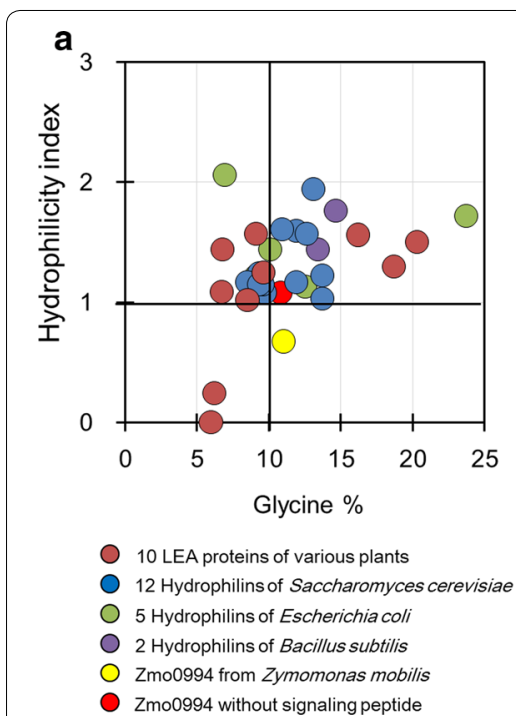

Fig. 7 E. coli harboring N-terminal truncated zmo0994 exhibited ethanol tolerance. a Plot construction based on hydrophilicity index and percentage of glycine of Zmo0994, hydrophilins from microbes, and LEA proteins from plants. The annotated hydrophilins were acquired from Garay-Arroyo et al. [46] and of LEA proteins from plants were used as a control set (Additional file 17: Note S1), and the hydrophilicity index was determined using webserver-based program available at https://web.expasy.org/protscale [70]. b E. coli harboring signal peptide truncated zmo0994 [E. coli ZMsig(-)] still exhibits ethanol tolerance. For the cell growth test, when the cell density grew to 0.5 of $\mathrm{OD}_{600}$, IPTG and ethanol were added to the culture at final concentrations of $0.1 \mathrm{mM}$ and $4 \%(\mathrm{v} / \mathrm{V})$, respectively. The experimental data present means \pm standard deviations from three independent experiments 
resulting in reduced ATP production by aerobic respiration that eventually leads to reduced biosynthesis of macromolecules and proliferation [54-56]. Notably, our RNA-seq results indicated that those genes up-regulated in response to Zmo0994 are mainly involved in ATP synthesis by aerobic respiration (Fig. 4). Indeed, 13 out of 21 genes involved in ATP synthesis significantly enhanced ethanol tolerance when expressed in E. coli (Fig. 6a). Thus, these genes, up-regulated in response to Zmo0994, might compensate for the decreased aerobic ATP synthesis due to increased membrane fluidity and ROS level under ethanol stress. Consistent with this interpretation, the intracellular ATP/ADP ratio of $E$. coli ZM was significantly higher than that of E. coli Emp (Fig. 5), indicating that ATP synthesis might be a key cellular response for stress tolerance. Although most of the tested genes for ATP synthesis in this study were previously reported to be responsible for ethanol tolerance based on the transcriptome and proteome analysis $[54,57,58]$, this is the first study to verify their role in ethanol and HMF tolerance. Considering that ATP participates in many cellular processes as a major substrate for energy production, manipulation of ATP supply could be a powerful tool to enhance tolerance to abiotic stresses [59]. Herein, we also established that three genes for multi-drug efflux pumps (tolC, $k e f B$, and $m d t G$ ) and four genes for cell wall biogenesis ( $m r a Y$ and $m u r C D F)$ enhanced ethanol tolerance. Specifically, murCDF genes for peptidoglycan synthesis are involved in ATP binding and hydrolysis. Several efflux pumps, such as AcrAB-TolC in E. coli, were experimentally verified to enhance solvent tolerance by exporting a broad range of chemicals [8]. The murD gene product for peptidoglycan biosynthesis was confirmed to be beneficial in conferring ethanol stress [60], while the murCF and $m r a Y$ genes were firstly verified to be responsible for stress in this study.

On the other hand, a total of 70 genes commonly upregulated by ethanol stress in both $E$. coli $\mathrm{ZM}$ and $E$. coli Emp were mainly involved in protein folding (chaperone), ROS detoxification, DNA damage repair, anaerobic metabolism, and rRNA processing (16S and 23S) (Additional file 4: Figure S4). Among these, several genes could be genetic targets for abiotic stress tolerance, such as phage shock protein (Psp) and DNA-binding protein from starved cells (Dps). The $p s p$ operon is known to play a key role in maintaining proton motive force by suppressing membrane leakage under nutrient- or energy-limited conditions [26]. Thus, Psp is regarded as a different type of envelope stress responses, which is distinct from periplasmic response proteins (e.g., CpxP) induced by ethanol $[31,61]$. Especially, $p s p A$, the regulator of $p s p$ operon, is a notable gene in that it could be a potential target for multi-stress tolerance in the development of industrial microorganism, because toxic compounds typically attack cell membranes, resulting in an increase of membrane fluidity [61]. Meanwhile, Dps binds the genomic DNA non-specifically during stationary phase, forming a highly ordered and stable Dps-genomic DNA complex, which is condensed and protected from diverse damages [62]. It protects DNA from oxidative damage by sequestering intracellular $\mathrm{Fe}^{2+}$ ion and storing it in the form of $\mathrm{Fe}^{3+}$ oxyhydroxide mineral, which can be released after reduction. One hydrogen peroxide oxidizes two $\mathrm{Fe}^{2+}$ ions, preventing hydroxyl radical production by the Fenton reaction [63]. In addition, Dps protects the cell from UV and gamma irradiation, iron and copper toxicity, thermal stress, and acid shocks [62, 64]. Another interesting observation in this study is that approximately $11 \%$ of the genes upregulated are rRNA components (rrsCDHG, $\operatorname{rrdACDH}$ ) by ethanol stress. Recently, it was reported that an rRNA variant (e.g., $r r s H)$ affects the expression of general stress response protein regulated by $\operatorname{RpoS}\left(\sigma^{38}\right)$ [65]. Thus, manipulation of genes coding the components for transcription and translation could be a potential tool for stress tolerance $[66,67]$.

\section{Conclusions}

The development of robust microbes for lignocellulosebased processes is essential for cost reduction in industrial-scale fermentation. Thus, a variety of efforts from metabolic engineering to omics analyses have been employed to date. In this study, we identified the functionally uncharacterized protein, Zmo0994, a novel small LEA-like protein from $Z$. mobilis, as a putative regulator of gene clusters, involved in aerobic respiration for ATP synthesis. Its major effect was a significant enhancement of tolerance to abiotic stresses, such as ethanol and inhibitors derived from lignocellulose pretreatment, when expressed in E. coli. In this regard, this discovery has significant implications in the development of robust microbes for efficient industrial fermentation processes.

\section{Methods}

\section{Bacterial strains, plasmids, and growth conditions}

The bacterial strains, plasmids, and primers used in this study are listed in Table S10 (Additional file 15). $Z$. mobilis subsp. mobilis ZM4 (ATCC 31,821) was grown at $30{ }^{\circ} \mathrm{C}$ and $80-200 \mathrm{rpm}$ in RM medium $(20 \mathrm{~g} / \mathrm{L}$ of glucose, $10 \mathrm{~g} / \mathrm{L}$ of yeast extract, $2 \mathrm{~g} / \mathrm{L}$ of $\mathrm{KH}_{2} \mathrm{PO}_{4} ; \mathrm{pH}$ 6.0). E. coli BL21(DE3) was used as the host for the expression of a target protein cloned in pET21a vector. E. coli strains were incubated at $37{ }^{\circ} \mathrm{C}$ in Luria-Bertani (LB) supplemented with ampicillin at $100 \mu \mathrm{g} / \mathrm{mL}$. 
Fermentation and purification of extracellular proteins from Z. mobilis

Z. mobilis cells grown to the exponential growth phase (2.0 of $\left.\mathrm{OD}_{600}\right)$ in $\mathrm{RM}$ broth were harvested and transferred into $1 \mathrm{~L}$ of RM containing glucose $80 \mathrm{~g} / \mathrm{L}$. The initial cell density was adjusted to approximately 0.8 of $\mathrm{OD}_{600}$. During the incubation at $30{ }^{\circ} \mathrm{C}$ and $80 \mathrm{rpm}$ without a gas fed, cell growth was monitored by $\mathrm{OD}_{600}$ and glucose and ethanol concentrations were measured using a high-performance liquid chromatography (HPLC; Waters, Milford, MA) equipped with an Aminex HPX$87 \mathrm{H}$ column (Bio-Rad, Hercules, CA). The column temperature was set at $65{ }^{\circ} \mathrm{C}$ and $0.5 \mathrm{mM} \mathrm{H}_{2} \mathrm{SO}_{4}$ solution was used as the mobile phase at a constant flow rate of $0.5 \mathrm{~mL} / \mathrm{min}$. Peaks were detected by a refractive index detector (RID) at $55{ }^{\circ} \mathrm{C}$ and were quantified according to calibration curves of glucose and ethanol.

For the purification of extracellular proteins, the supernatant from $1 \mathrm{~L}$ of $Z$. mobilis culture was separated every $2-4 \mathrm{~h}$ by centrifuging at $8000 \mathrm{rpm}$ for $20 \mathrm{~min}$ at $4{ }^{\circ} \mathrm{C}$ and was passed through a $0.22 \mu \mathrm{m}$ sterile vacuum filter. The supernatant was mixed with either $1 \mathrm{~mL}$ of SP-sepharose or Q-sepharose fast flow resin (GE healthcare, Marlborough, MA) for anion or cation exchange chromatography, respectively, at $4{ }^{\circ} \mathrm{C}$ for $1 \mathrm{~h}$. Then, the mixture was poured into a glass column and immobilized proteins were eluted with a $0-1.0 \mathrm{mM} \mathrm{NaCl}$ gradient in $50 \mathrm{mM}$ phosphate buffer ( $\mathrm{pH}$ 7.0). Finally, the purified proteins were visualized by SDS-PAGE analysis.

\section{Mass spectrometry analysis and protein identification}

Following an SDS-PAGE analysis, the bands corresponding to proteins of interest including Zmo0994 were cut out of the gel, equilibrated in $50 \mu \mathrm{L}$ of $50 \mathrm{mM}$ ammonium bicarbonate, and subsequently alkylated with $10 \mathrm{mM}$ dithiothreitol (DTT) and $100 \mathrm{mM}$ iodoacetamide (IAA), followed by destaining and desiccation with acetonitrile. Gel plugs were rehydrated with $50 \mathrm{mM}$ ammonium bicarbonate containing 6.6\% (w/v) trypsin (Promega, Madison, WI) and digested overnight. Peptides were extracted using 50\% (v/v) acetonitrile and $0.1 \%(\mathrm{v} / \mathrm{v})$ trifluoroacetic acid (TFA) into a final volume of $50 \mu \mathrm{L}$, and the resulting extracts were freeze-dried and resuspended in $10 \mu \mathrm{L}$ of $0.1 \%$ formic acid. After samples were washed in situ with $0.1 \%$ TFA and left to dry again, $0.2 \mu \mathrm{L}$ of matrix (e.g., $\alpha$-cyano-4-hydroxycinnamic acid in nitrocellulose/acetone) was applied to a mass spectrometer target plate. Then, MALDI-TOF PMF was performed using a Voyager-DE ${ }^{\mathrm{TM}}$ STR BioSpectrometry ${ }^{\mathrm{TM}}$ Workstation (Applied Biosystems, Warrington, UK). De-isotoped and calibrated spectra were used to generate peak lists, which were searched using MASCOT (www.matrixscie nce.com) mass spectrometry database search software to identify the proteins.

\section{Quantitative reverse transcription polymerase chain reaction (qRT-PCR)}

When $Z$. mobilis cells were grown to the early exponential phase at 0.5 of $\mathrm{OD}_{600}$, cells were either treated or non-treated with ethanol $(6 \%, v / v)$ to observe the expression patterns of $z$ mo0994. Total RNA was isolated from $10 \mathrm{~mL}$ culture using RNeasy Mini Kit (Qiagen, Hilden, Germany) and the isolated RNA was quantified using NanoDrop Spectrophotometer 2000 (Thermo Fisher Scientific, Wilmington, DE). Then, reverse transcription reactions were applied for cDNA synthesis with $1 \mu \mathrm{g}$ of total RNA with random hexamer (SuperScript ${ }^{\mathrm{TM}}$ II Reverse Transcriptase; Thermo Fisher Scientific). Finally, $z m o 0994$ and 16S rRNA genes were amplified from synthetic cDNA as a template with the designed primers: ZM_RT_Fwd and ZM_RT_Rev for $z m o 0994$; ZM_16s_ Fwd and ZM_16s_Rev for 16 s rDNA of Z. mobilis (Additional file 15: Table S10).

\section{Assays for tolerance and viability}

For spot assay, overnight culture of E. coli ZM and E. coli Emp strains were diluted at 0.02 of $\mathrm{OD}_{600}$ into $100 \mathrm{~mL}$ of LB broth and were incubated at $37{ }^{\circ} \mathrm{C}$. When E. coli cells were grown to the early exponential phase at 0.5 of $\mathrm{OD}_{600}, 5 \mu \mathrm{L}$ of tenfold serially diluted cell suspensions was spotted onto LB-ampicillin plate containing $4-8 \%(\mathrm{v} / \mathrm{v})$ of ethanol, $10-30 \mathrm{mM}$ of furfural, and 10-30 mM of HMF with addition of $0.1 \mathrm{mM}$ isopropyl $\beta$-D-1-thiogalactopyranoside (IPTG). Then, the plates were incubated at $37^{\circ} \mathrm{C}$ and examined for $16-36 \mathrm{~h}$. Tolerance of $E$. coli ZM to thermal stress was examined in a similar manner on LB plates at $44-48{ }^{\circ} \mathrm{C}$. In addition, for viability assay, $E$. coli cells were grown to 0.5 of $\mathrm{OD}_{600}$, corresponding to approximately $2.57 \times 10^{8} \mathrm{CFU} / \mathrm{mL}$, and they were exposed to $6 \%(\mathrm{v} / \mathrm{v})$ ethanol, $20 \mathrm{mM}$ furfural, $20 \mathrm{mM}$ HMF, and $48{ }^{\circ} \mathrm{C}$ for $12-48 \mathrm{~h}$. Viable cells were determined by colony counting for $24 \mathrm{~h}$ at $12 \mathrm{~h}$ interval. Finally, the viability of survived cells under various stresses was expressed as the percentage of initial CFU/ $\mathrm{mL}$ after $12-24 \mathrm{~h}$.

\section{Whole-transcriptome shotgun sequencing (RNA-seq) and analysis}

When E. coli ZM and E. coli Emp cells were grown to the early exponential phase at 0.5 of $\mathrm{OD}_{600}$, cell cultures were either treated or non-treated with ethanol (4\%,v/v). After $4 \mathrm{~h}$, cell pellets from the cultures were collected by centrifuging at $8000 \mathrm{~g}$ for $10 \mathrm{~min}$ at $4{ }^{\circ} \mathrm{C}$ and washed twice with ice-cold $50 \mathrm{mM}$ phosphate-buffered saline (PBS). Then, the pellets were quickly placed in liquid nitrogen and 
were sent to DNALink (Seoul, Korea) for RNA-seq. RNA extraction, rRNA removal, RNA fragmentation, cDNA synthesis, adapter ligation, and PCR implication were performed to construct a cDNA library. Agilent 2100 Bioanalyzer (Agilent Technologies, Santa Clara, CA) verified the quality of the amplified library. Sequencing was performed using Illumina HiSeq 2500 system (Illumina, San Diego, CA) with 200 bp read length. Clean reads for each sample were obtained, filtered, and mapped to the reference genome of $E$. coli K12 MG1655 by Tophat (version 2.0.13) [68]. The aligned results were added to Cuffdiff (version 2.2.0; https://cole-trapnell-lab.github.io/ cufflinks/cuffdiff/) for library normalization and for identification of differentially expressed genes (DEGs). The significance of differences in gene expression was defined as $p<0.05$ and $>\log _{2}$ twofold. The gene ontology analysis was performed with DAVID (version 6.8; https://david .abcc.ncifcrf.gov/).

\section{Modification of $5^{\prime}$-untranslated region (5'-UTR)}

The $5^{\prime}$-UTR variants of $z m o 0994$ were constructed as described previously ${ }^{23}$. Briefly, UTR Designer (https:// sbi.postech.ac.kr/utr_designer) was used to predict the expression level of $z m o 0994$ with a particular mRNA sequence in 5'-UTR. The entire pET21(a)::zm0994 plasmid was used as the PCR template with $5^{\prime}$-phosphorylated primers (Z_U1_Forward, Z_U2_Forward, and UTR_Reverse) to generate the $5^{\prime}$-UTR variants (Additional file 15: Table S10). The resulting PCR products were purified via gel extraction using the QIAquick gel extraction kit (Qiagen, Hilden, Germany) and the template DNA was eliminated by treatment with DpnI (NEB) at $37{ }^{\circ} \mathrm{C}$ for $3 \mathrm{~h}$. The PCR products were bluntend ligated with T4 DNA ligase (NEB) at $16{ }^{\circ} \mathrm{C}$ for $4 \mathrm{~h}$ and used to transform E. coli DH5 $\alpha$ strain. Purified plasmids from transformants were sequenced by Macrogen (Seoul, Korea) and the screened plasmids containing the $z m o 0994$ gene with the targeted $5^{\prime}$-UTR sequence were transformed into $E$. coli BL21(DE3).

\section{Western blot}

After E. coli strains grown at 0.5 of $\mathrm{OD}_{600}$ were treated with $0.1 \mathrm{mM}$ of IPTG in $10 \mathrm{~mL}$, cell pellets from $2 \mathrm{~mL}$ of cell cultures were collected at various time points and resuspended in $100 \mu \mathrm{L}$ of lysis buffer [ $50 \mathrm{mM}$ Tris- $\mathrm{HCl}$, $150 \mathrm{mM} \mathrm{NaCl}, 1$ tablet of protease inhibitor (Roche, Mannheim, Germany)]. The resuspended cells were disrupted using glass beads (425-600 $\mu \mathrm{m}$ size; SigmaAldrich, St. Louis, MO) and debris was removed by centrifuging at $14,000 \mathrm{rpm}$ for $15 \mathrm{~min}$ at $4{ }^{\circ} \mathrm{C}$. The supernatant proteins were resolved by $12 \%$ sodium dodecyl sulfate-polyacrylamide gel electrophoresis (SDS-PAGE) and transferred to a polyvinylidene difluoride (PVDF) membrane (Bio-Rad, Hercules, CA). For detecting Histagged Zmo0994, anti- $6 \times$ histidine antibody raised in rabbit (Santa Cruz Biotechnology, Dallas, TX) against the Zmo0994 (in 1:10,000 dilution) and a goat anti-rabbit antibody (in 1:20,000 dilution) were used. Finally, protein bands were visualized by detection of horseradish peroxidase-conjugated secondary anti-rabbit antibodies. The band intensities were quantified with NIH image J (Version 1.61; National Institutes of Health, Bethesda, MD).

\section{Measurement of relative fitness}

Overnight culture of $E$. coli harboring each gene was diluted at 0.02 of $\mathrm{OD}_{600}$ into $100 \mathrm{~mL}$ of LB broth and incubated at $37^{\circ} \mathrm{C}$. When the cell density reached 0.5 of $\mathrm{OD}_{600}$, IPTG and ethanol were added to the culture at final concentrations of $0.1 \mathrm{mM}$ and $4 \%(\mathrm{v} / \mathrm{v})$, respectively. Then, cell growth was monitored by measuring $\mathrm{OD}_{600}$ for $24 \mathrm{~h}$ at $2 \mathrm{~h}$ intervals. Finally, relative fitness was calculated by the following equation:

$$
\begin{aligned}
& \text { Relative fitness } \\
& =\frac{\ln \left(\frac{\text { OD600 at } 16 \mathrm{~h}}{\text { OD600 at } 0 \mathrm{~h}}\right) \text { in the presence of ethanol }(4 \%, \mathrm{v} / \mathrm{v} /)}{\ln \left(\frac{\text { OD600 at } 16 \mathrm{~h}}{\text { OD600 at } 0 \mathrm{~h}}\right) \text { in the absence of ethanol }}
\end{aligned}
$$

Finally, Student's $t$-test was performed using STATISTICA 7 for the statistical analysis.

\section{Supplementary information}

Supplementary information accompanies this paper at https://doi. org/10.1186/s13068-020-01790-0.

\section{Additional file 1: Figure S1. SDS-PAGE analysis of extracellular proteins} produced by Zymomonas mobilis.

Additional file 2: Figure S2. MASCOT search results from the MS-MS data generated for Zmo0994 (uncharacterized protein)

Additional file 3: Figure S3. Blast results of Zmo0994 (UniProt accession number: Q5NNU2). a. Q9LF88, LEA protein from Arabidopsis thaliana; $b$. A0A2K3MNT4, Group 3 LEA protein from Trifolium pretense.

Additional file 4: Figure S4. Quantitative RT-PCR analysis of zmo0994 expression in Z. mobilis in both the absence and presence of ethanol.

Additional file 5: Figure S5. Western-blot results showing the expression level of Zmo0994.

Additional file 6: Figure S6. Differentially expressed genes of E. coli ZM and $E$. coli Emp in the presence of $4 \%(\mathrm{~V} / \mathrm{V})$ compared to those in the absence of ethanol.

Additional file 7: Table S1. Genes with $>\log _{2}$ twofold increase in their expression level in E. coli ZM in the presence of 4\% ( $\mathrm{v} / \mathrm{v})$ ethanol compared to in the absence of ethanol, using a p-value threshold less than 0.05 ; Table S2. Genes with $>\log _{2}$ twofold increase in their expression level in $E$. coli Emp in the presence of $4 \%(\mathrm{~V} / \mathrm{V})$ ethanol compared to in the absence of ethanol, using a $p$-value threshold less than 0.05 .

Additional file 8: Table S3. Genes with $>\log _{2}$ twofold decrease in their expression level in E. coli ZM in the presence of $4 \%(\mathrm{v} / \mathrm{V})$ ethanol compared to in the absence of ethanol, using a $p$-value threshold less than 0.05 ; Table S4. Genes with $>\log _{2}$ twofold decrease in their expression level in $E$. 
coli Emp in the presence of $4 \%(\mathrm{v} / \mathrm{v})$ ethanol compared to in the absence of ethanol, using a $p$-value threshold less than 0.05 .

Additional file 9: Table S5. Genes with $>\log _{2}$ twofold decrease in their expression level in E. coli ZM as compared to E. coli Emp in the presence of ethanol $(4 \%, v / v)$, using a $p$-value threshold less than 0.05; Table S6. Genes with $>\log _{2}$ twofold decrease in their expression level in E. coli ZM as compared to $E$. coli Emp in the absence of ethanol, using a $p$-value threshold less than 0.05 .

Additional file 10: Table S7. Genes with $>\log _{2}$ twofold increase in their expression level in E. coli ZM as compared to E. coli Emp in the presence of ethanol $(4 \%, v / v)$, using a $p$-value threshold less than 0.05; Table $\mathbf{S 8 .}$ Genes with $>\log _{2}$ twofold increase in their expression level in E. coli ZM as compared to E. coli Emp in the absence of ethanol, using a $p$-value threshold less than 0.05 .

Additional file 11: Table S9. Tested 33 genes, up-regulated in the absence or presence of $4 \%(\mathrm{v} / \mathrm{v})$ ethanol with $>\log 2$ twofold change in their expression level by Zmo0994 expression.

Additional file 12: Figure S7. Growth profiles of E. coli strains harboring the indicated gene in the absence and presence of ethanol $(4 \%, \mathrm{~V} / \mathrm{V})$; Figure S8. Growth profiles of E. coli strains harboring the indicated gene in the absence and presence of $10 \mathrm{mM} \mathrm{HMF}$.

Additional file 13: Figure S9. Confocal microscopy analysis for the localization of GFP-fused Zmo099.

Additional file 14: Figure S10. Results of substitution of cold shock protein with Zmo0994 for RNA chaperone test.

Additional file 15: Table S10 Bacterial strains, plasmids, and primers used in this study

Additional file 16: Figure S11. Heat map of functionally classified DEGs by Zmo0994

Additional file 17: Note S1. Amino acid sequences of hydrophilins from microorganisms and LEA proteins from plants.

\section{Abbreviations}

LEA: Late embryogenesis abundant; ATP: Adenosine triphosphate; HMF: 5'-Hydroxymethylfurfural; gTME: Global transcription machinery engineering; qRT-PCR: Quantitative reverse transcription polymerase chain reaction; CFU: Colony-forming unit; 5'-UTR: 5'-Untranslated region; ADP: Adenosine diphosphate; DEG: Differentially expressed genes; NADH: Nicotinamide adenine dinucleotide hydrogen; RMF: Ribosome modulation factor; HSP12: Heat shock protein 12; RNA: Ribonucleic acid; Psp: Phage shock protein; Dps: DNA-binding protein; UV: Ultraviolet; RM: Rich medium; HPLC: High-performance liquid chromatography; RID: Refractive index detector; IPTG: Isopropyl $\beta$-D-1thiogalactopyranoside; SDS-PAGE: Sodium dodecyl sulfate-polyacrylamide gel electrophoresis.

\section{Acknowledgements}

The article-processing charge was supported by School of Life Sciences and Biotechnology for BK21 PLUS Program for Korea University.

\section{Authors' contributions}

KHK designed the research, supervised the project, and wrote the manuscript. JY designed the research and contributed to the writing of the manuscript. JY, HEK, YHJ, and DHK performed experiments and analyzed the data. JK generated and provided analytical tools. ARW aided in interpreting the results and provided critical revision. All authors read and approved the final manuscript.

\section{Funding}

This work was supported by the Mid-career Researcher Program (2020R1A2B5B02002631) and the C1 Gas Refinery Program (2016M3D3A1A01913268), both through the National Research Foundation (NRF) of Korea. KHK acknowledges the grant support by Korea University (the Institute of Biomedical Science and Food Safety, Korea University Food Safety Hall, 2020).

\section{Availability of data and materials}

The datasets used and/or analyzed during the current study are available from the corresponding author on reasonable request.

\section{Ethics approval and consent to participate}

Not applicable.

\section{Consent for publication}

Not applicable.

\section{Competing interests}

The authors declare that they have no competing interests.

\section{Author details}

${ }^{1}$ Department of Biotechnology, Graduate School, Korea University, Seoul 02841, Republic of Korea. ${ }^{2}$ School of Food Science and Biotechnology, Kyungpook National University, 80 Daehak-ro, Buk-gu, Daegu 41566, Republic of Korea. ${ }^{3}$ Department of Biosciences, Durham University, South Road, Durham DH1 3LE, UK.

Received: 26 February 2020 Accepted: 16 August 2020

Published online: 26 August 2020

\section{References}

1. Hahn-Hägerdal B, Galbe M, Gorwa-Grauslund MF, Lidén G, Zacchi G. Bio-ethanol-the fuel of tomorrow from the residue of today. Trends Biotechnol. 2006;24:549-56.

2. Lynd LR. The grand challenge of cellulosic biofuels. Nat Biotechnol. 2017:35:912-5.

3. Kumar P, Barrett DM, Delwiche MJ, Stroeve P. Methods for pretreatment of lignocellulosic biomass for efficient hydrolysis and biofuel production. Ind Eng Chem Res. 2009;48:3713-29.

4. Yang B, Wyman CE. Pretreatment: the key to unlocking low-cost cellulosic ethanol. Biofuel Bioprod Biorefin. 2008;2:26-40.

5. Jönsson LF, Martín C. Pretreatment of lignocellulose: Formation of inhibitory by-products and strategies for minimizing their effects. Bioresour Technol. 2016;199:103-12.

6. Gibson BR, Lawrence SJ, Leclaire JP, Powell CD, Smart KA. Yeast responses to stresses associated with industrial brewery handling. FEMS Microbiol Rev. 2007:31:535-69.

7. Jin $\mathrm{H}$, Chen L, Wang J, Zhang W. Engineering biofuel tolerance in nonnative producing microorganisms. Biotechnol Adv. 2014;32:541-8.

8. Dunlop MJ, Dossani ZY, Szmidt HL, Chu HC, Lee TS, Keasling JD, Hadi MZ, Mukhopadhyay A. Engineering microbial biofuel tolerance and export using efflux pump. Mol Sys Biol. 2011;7:487.

9. Zingaro KA, Papoutsakis ET. GroESL overexpression imparts Escherichia coli tolerance to $i$-, $n$-, and 2-butanol, 1,2,4-butanetriol and ethanol with complex and unpredictable patterns. Metab Eng. 2013;15:196-205.

10. Alper H, Moxley J, Nevoigt E, Fink GR, Stephanopoulos G. Engineering yeast transcription machinery for improved ethanol tolerance and production. Science. 2006;8:1565-8.

11. Atsumi S, WU T, Machado IMP, Huang W, Chen P, Pellegrini M, Liao JC. Evolution, genomic analysis, and reconstruction of isobutanol tolerance in Escherichia coli. Mol Syst Biol. 2010;6:449.

12. Patnaik R, Louie S, Gavrilovic V, Perry K, Stemmer WPC, Ryan CM, del Cardayré S. Genome shuffling of Lactobacillus for improved acid tolerance. Nat Biotechnol. 2002;20:707-12.

13. Peabody GLV, Winkler J, Kao KC. Tools for developing tolerance to toxic chemicals in microbial systems and perspectives on moving the field forward and into the industrial setting. Curr Opin Chem Eng. 2014;6:9-17.

14. Banerjee S, Mudliar S, Sen R, Giri B, Satpute D, Chakrabarti T, Pandey RA. Commercializing lignocellulosic bioethanol: technology bottlenecks and possible remedies. Biofuels Bioprod Bioref. 2010;4:77-93.

15. Goodacre NF, Gerloff DL, Uetz P. Protein domains of unknown function are essential in bacteria. mBio. 2014;5:e00744-13.

16. Galperin MY, Koonin EV. From the genome sequence to "complete" understanding? Trends Biotechnol. 2010;28:398-406. 
17. Seo JS, Chong H, Park HS, Yoon KO, Jung C, Kim JJ, et al. The genome sequence of ethanologenic bacterium Zymomonas mobilis ZM4. Nat Biotechnol. 2005;23:63-8.

18. Umezawa T, Fujita M, Fujita Y, Yamaguchi-Shinozaki K, Shinozaki K. Engineering drought tolerance in plants: discovering and tailoring genes to unlock the future. Curr Opin Biotechnol. 2006;17:113-22.

19. Wang W, Vinocur B, Altman A. Plant response to drought, salinity and extreme temperatures: towards genetic engineering for stress tolerance. Planta. 2003:218:1-14

20. Ling $H$, Zeng $X$, Guo S. Functional insights into the late embryogenesis abundant (LEA) protein family from Dendrobium officinale (Orchidaceae) using an Escherichia coli system. Sci Rep. 2016;6:39693.

21. Goyal K, Walton $L$, Tunnacliffe A. LEA proteins prevent protein aggregation due to water stress. Biochem J. 2005;388:151-7.

22. Emanuelsson O, Brunak S, von Heijne $G$, Nielsen $H$. Locating proteins in the cell using TargetP SignalP and related tools. Nat Protoc. 2007;2:953-7.

23. Seo SW, Yang JS, Kim I, Yang J, Min BE, Kim S, et al. Predictive design of mRNA translation initiation region to control prokaryotic translation efficiency. Metab Eng. 2013;15:67-74.

24. Quan S, Koldewey P, Tapley T, Kirsch N, Ruane KM, Pfizenmaier J, et al. Genetic selection designed to stabilize proteins under uncovers a chaperone called Spy. Nat Struct Mol Biol. 2011;18:262-9.

25. Šeputienè $V$, Motiejūnas D, Sužiedèlis K, Tomenius H, Normark S, Melefors Ö, et al. Molecular characterization of the acid-inducible asr gene of Escherichia coli and its role in acid stress response. J Bacteriol. 2003;185:2475-84.

26. Darwin AJ. The phage shock protein response. Annu Rev Microbiol. 2016;70:83-101.

27. Loos J, Krämer R, Sahm H, Sprenger GA. Sorbitol promotes growth of Zymomonas mobilis in environments with high concentrations of sugar: evidence for a physiological function of glucose-fructose oxidoreductase in osmoprotection. J Bacteriol. 1994;176:7688-93.

28. Purvis JE, Yomano LP, Ingram LO. Enhanced trehalose production improves growth of Escherichia coli under osmotic stress. Appl Environ Microbiol. 2005;71:3761-9.

29. Pérez JM, Arenas FA, Pradenas GA, Sandoval JM, Vásquez CC. Escherichia coli YqhD exhibits aldehyde reductase activity and protects from the harmful effect of lipid peroxidation-derived aldehydes. J Biol Chem. 2008;283:7346-53.

30. Imlay JA. The molecular mechanisms and physiological consequence of oxidative stress: lessons from a model bacterium. Nat Rev Microbiol. 2013;11:443-54.

31. Thede GL, Arthur DC, Edwards RA, Buelow DR, Wong JL, Raivio T, et al. Structure of the periplasmic stress response protein CpxP. J Bacteriol. 2011;193:2149-57.

32. Siegele DA. Universal stress proteins in Escherichia coli. J Bacteriol. 2005;187:6253-4.

33. Angelini S, Gerez C, Ollagnier-de Choudens S, Sanakis Y, Fontecave M, Barras F, et al. NfuA, a new factor required for maturing Fe/S proteins in Escherichia coli under oxidative stress and iron starvation conditions. J Biol Chem. 2008;283:14084-91.

34. Imlay JA. Cellular defenses against superoxide and hydrogen peroxide. Annu Rev Biochem. 2008:77:755-76.

35. Ackerley DF, Gonzalez CF, Keyhan M, Blake IIM, Matin A. Mechanism of chromate reduction by the Escherichia coli protein, NfsA, and the role of different chromate reductases in minimizing oxidative stress during chromate reduction. Environ Microbiol. 2004;6:851-60.

36. Yura T, Nagai $H$, Mori $H$. Regulation of the heat-shock response in bacteria. Annu Rev Microbiol. 1993:47:321-50.

37. Arsène F, Tomoyasu T, Bukau B. The heat shock response of Escherichia coli. Int J Food Microbiol. 2000;55:3-9.

38. Weber H, Polen T, Heuveling J, Wendisch VF, Hengge R. Genome-wide analysis of the general stress response network in Escherichia coli: $\sigma^{S}$ dependent genes, promoters, and sigma factor selectivity. J Bacteriol. 2005;187:1591-603.

39. Karas VO, Westerlaken I, Meyer AS. The DNA-binding protein from starved cells (Dps) utilizes dual functions to defend cells against multiple stresses. J Bacteriol. 2015;197:3206-15.

40. Acharya S, Foster PL, Brooks P, Fishel R. The coordinated functions of the $E$. coli MutS and MutL proteins in mismatch repair. Mol Cell. 2003;12:233-46.
41. Stracy M, Jaciuk M, Uphoff S, Kapanidis AN, Nowotny M, Sherratt DJ, et al. Single-molecule imaging of UvrA and UvrB recruitment to DNA lesions in living Escherichia coli. Nat Commun. 2016;7:12568.

42. Yamanaka K, Zheng W, Crooke E, Wang YH, Inouye M. CspD, a novel DNA replication inhibitor induced during the stationary phase in Escherichia coli. Mol Microbiol. 2001;39:1572-84.

43. Hoekstra FA, Golvina EA, Buitink J. Mechanisms of plant desiccation tolerance. Trends Plant Sci. 2001;6:431-8.

44. Mertens J, Aliyu H, Cowan DA. LEA proteins and the evolution of the WHy Domain. Appl Environ Microbiol. 2018;84:e00539-e618.

45. Gao J, Lan T. Functional characterization of the late embryogenesis abundant (LEA) protein gene family from Pinus tabuliformis (Pinaceae) in Escherichia coli. Sci Rep. 2016;6:19467.

46. Garay-Arroyo A, Colmenero-Flores JM, Garciarrubio A, Covarrubias AA. Highly hydrophilic proteins in prokaryotes and eukaryotes are common during conditions of water deficit. J Biol Chem. 2000;275:5668-744.

47. Battaglia M, Olvera-Carrillo Y, Garciarrubio A, Campos F, Covarrubias AA. The enigmatic LEA proteins and other hydrophilins. Plant Physiol. 2008;148:6-24.

48. Niven GW, El-Sharoud WM. Ribosome modulation factor. In: Physiology B, editor. Springer. Berlin: Heidelberg; 2008. p. 293-311.

49. Mtwisha L, Brandt W, McCready S, Lindsey GG. HSP12 is a LEA-like protein in Saccharomyces cerevisiae. Plant Mol Biol. 1998;37:513-21.

50. Sales K, Brandt W, Rumbak E, Lindsey G. The LEA-like protein HSP12 in Saccharomyces cerevisiae has a plasma membrane location and protects membranes against desiccation and ethanol-induced stress. Biochim Biophys Acta. 2000;1463:267-78.

51. Welker S, Rudolph B, Frenzel E, Hagn F, Liebisch G, Schmitz G, et al. Hsp12 is an intrinsically unstructured stress protein that folds upon membrane association and modulates membrane function. Mol Cell. 2010;39:507-20.

52. Mertens J, Aliyu H, Cowan DA. LEA proteins and the evolution of the WHy domain. Appl Environ Microbiol. 2018;84:e00539-e618.

53. Kim JS, Park SJ, Kwak KJ, Kim YO, Kim JY, Song J, et al. Cold shock domain proteins and glycine-rich RNA-binding proteins from Arabidopsis thaliana can promote the cold adaptation process in Escherichia coli. Nucleic Acids Res. 2007:35:506-16.

54. Cao H, Wei D, Yang Y, Shang Y, Li G, Zhou Y, et al. Systems-level understanding of ethanol-induced stresses and adaptation in E. coli. Sci Rep. 2017;7:44150.

55. Woodruff LB, Pandhal J, Ow SY, Karimpour-Fard A, Weiss SJ, Wright PC, et al. Genome-scale identification and characterization of ethanol tolerance genes in Escherichia coli. Metab Eng. 2013;15:124-33.

56. Huffer S, Clark ME, Ning JC, Blanch HW, Clark DS. Role of alcohols in growth, lipid composition, and membrane fluidity of yeasts, bacteria, and archaea. Appl Environ Microbiol. 2011;77:6400-8.

57. Horinouchi T, Tamaoka K, Furusawa C, Ono N, Suzuki S, Hirasawa T, et al. Transcriptome analysis of parallel-evolved Escherichia coli strains under ethanol stress. BMC Genomics. 2010;11:579.

58. Kabir MM, Shimizu K. Metabolic regulation analysis of icd-gene knockout Escherichia coli based on 2D electrophoresis with MALDI-TOF mass spectrometry and enzyme activity measurements. Appl Microbiol Biotechnol. 2004;65:84-96.

59. Zhou J, Liu L, Shi Z, Du G, Chen J. ATP in current biotechnology: regulation, applications and perspectives. Biotechnol Adv. 2009;27:94-101.

60. Goodarzi H, Bennett BD, Amini S, Reaves ML, Hottes AK, Rabinowitz JD, et al. Regulatory and metabolic rewiring during laboratory evolution of ethanol tolerance in E. coli. Mol Syst Biol. 2010;6:378.

61. Danese PN, Silhavy TJ. CpxP, a stress-combative member of the Cpx regulon. J Bacteriol. 1998;180:831-9.

62. Manganelli R, Gennaro ML. Protecting from envelope stress: variations on the phage-shock-protein theme. Trends Microbiol. 2017;25:205-16.

63. Zhao G, Ceci P, Ilari A, Giangiacomo L, Laue TM, Chiancone E, et al. Iron and hydrogen peroxide detoxification properties of DNA-binding protein from starved cells A ferritin-like DNA-binding protein of Escherichia coli. J Biol Chem. 2002;277:27689-96.

64. Calhoun LN, Kwon YM. Structure, function and regulation of the DNAbinding protein Dps and its role in acid and oxidative stress resistance in Escherichia coli: a review. J Appl Microbiol. 2011;110:375-86. 
65. Janissen R, Arens MM, Vtyurina NN, Rivai Z, Sunday ND, Eslami-Mossallam $B$, et al. Global DNA compaction in stationary-phase bacteria does not affect transcription. Cell. 2018;174:1188-99.

66. Kurylo CM, Parks MM, Juette MF, Zinshteyn B, Altman RB, Thibado JK, et al. Endogenous rRNA sequence variation can regulate stress response gene expression and phenotype. Cell Rep. 2018;25:236-48.

67. Haft RJF, Keating DH, Schwaegler T, Schwalbach MS, Vinokur J, Tremaine $\mathrm{M}$, et al. Correcting direct effects of ethanol on translation and transcription machinery confers ethanol tolerance in bacteria. Proc Natl Acad Sci USA. 2014;111:2576-85.

68. Kim D, Pertea G, Trapnell C, Pimentel H, Kelley R, Salzberg SL. TopHat2: accurate alignment of transcriptomes in the presence of insertions, deletions and gene fusions. Genome Biol. 2013;14:R36.
69. Yang J. Enhanced bioethanol production by Zymomonas mobilis in response to the quorum sensing molecules Al-2. Doctoral thesis, Durham University, United Kingdom; 2011.

70. Kyte J, Doolittle RF. A simple method for displaying the hydropathic character of a protein. J Mol Biol. 1982:157:105-32.

\section{Publisher's Note}

Springer Nature remains neutral with regard to jurisdictional claims in published maps and institutional affiliations.
Ready to submit your research? Choose BMC and benefit from:

- fast, convenient online submission

- thorough peer review by experienced researchers in your field

- rapid publication on acceptance

- support for research data, including large and complex data types

- gold Open Access which fosters wider collaboration and increased citations

- maximum visibility for your research: over 100M website views per year

At BMC, research is always in progress.

Learn more biomedcentral.com/submissions 